\title{
Correction to: Differentiation of endogenous and exogenous $\gamma$-Hydroxybutyrate in rat and human urine by GC/C/IRMS
}

\author{
Hyojeong Kim ${ }^{1,2}$. Dong-Hun Lee ${ }^{3} \cdot$ Ahra Go $^{1} \cdot$ Meejung Park ${ }^{4}$. Sanggil Choe ${ }^{4} \cdot$ Sanghwan In $^{4} \cdot$ Eunmi Kim $^{4}$. \\ Hunjoo Lee ${ }^{5} \cdot$ Kyung-Hoon $\mathrm{Shin}^{3} \cdot$ Eunyoung $\mathrm{Han}^{1,2}$
}

Published online: 28 August 2019

(C) Springer-Verlag GmbH Germany, part of Springer Nature 2019

Correction to: International Journal of Legal Medicine (2019) https://doi.org/10.1007/s00414-019-02052-x

The above article was published online with incorrect author names. The right spelling should be Dong-Hun Lee instead of Donghun Lee, Sanggil Choe instead of Sanggil Choi. The correct names are presented here. The original article has been corrected.

Publisher's note Springer Nature remains neutral with regard to jurisdictional claims in published maps and institutional affiliations.

The online version of the original article can be found at https://doi.org/ 10.1007/s00414-019-02052-x

Kyung-Hoon Shin

shinkh@hanyang.ac.kr

$\triangle$ Eunyoung Han

homepage2600@duksung.ac.kr

1 College of Pharmacy, Duksung Women's University, Seoul 01369, South Korea

2 Innovative Drug Center, DuksungWomen's University, Seoul, South Korea

3 Department of Marine Science and Convergent Technology, Hanyang University, Ansan 15588, South Korea

4 National Forensic Service, Wonju, South Korea

5 CHEM.I.NET,Ltd, Room 302, 773-3, Mok-dong, Yangcheon-gu, Seoul, South Korea 